\title{
Penyusunan SOP Incident Management pada PT. RST dan PT. XYZ Berdasarkan ITIL 3 Versi 2011
}

\author{
I Putu Deny Arthawan Sugih Prabowo', Indah Nur Rachmawati², Yanti Rahmawati \\ Program Studi Sistem Informasi \\ Institut Teknologi Kalimantan \\ Balikpapan, Indonesia \\ e-mail: ${ }^{1}$ putudeny.asp@lecturer.itk.ac.id, ${ }^{2} 10161045 @$ student.itk.ac.id, ${ }^{3} 10161094 @$ student.itk.ac.id \\ Diajukan: 4 Januari 2021; Direvisi: 16 Maret 2021; Diterima: 26 Maret 2021
}

\begin{abstract}
Abstrak
Saat ini, IT berperan sebagai enabler atau bahkan driver bagi bisnis organisasi untuk mencapai keunggulan bersaing organisasi tersebut. Hal ini menjadi tantangan bagi suatu perusahaan dalam mengelola kualitas layanannya yang berbasis IT (IT services). Bagaimanapun gangguan (incident) yang dialami oleh IT services kerap menimbulkan business impacts bagi suatu perusahaan penyedia IT services (IT services provider). Dengan demikian, incident perlu dikontrol dalam proses incident management yang mengacu pada best practices Information Technology Infrastructure Library (ITIL) untuk meminimalisir business impacts yang diakibatkan oleh incident. Beberapa perusahaan seperti PT. RST dan PT. XYZ belum sepenuhnya menerapkan incident management sehingga tidak semua incident yang terjadi pada IT services dari masing-masing perusahaan tersebut terpantau dan terkontrol dengan baik. Dengan demikian, studi ini bertujuan untuk menyusun Standard Operating Procedure (SOP) incident management pada PT. RST dan PT. XYZ berdasarkan ITIL 3 versi 2011. Data tentang kondisi terkini perusahaan yang menjadi bahan penyusunan SOP ini, diperoleh dari wawancara secara daring dengan process owner di PT. RST dan PT. $X Y Z$. Setelah SOP ini disusun, SOP ini diverifikasi dengan process owner masing-masing perusahaan tersebut. Dalam rangka continual improvement, SOP pada PT. RST dan PT. XYZ perlu dievaluasi kembali berdasarkan ITIL 4.
\end{abstract}

Kata kunci: SOP, Incident Management, Incident, ITIL, IT Services.

\begin{abstract}
IT has the role as the enabler or even the driver of the organizational business currently for achieving the organizational competitive advantage. It is the challenges of a company for managing its IT services quality. However, the incidents of IT services often make the business impacts for a company as the IT services provider. Thus, the incidents need to be controlled in incident management that refers to Information Technology Infrastructure Library (ITIL) best practices, to minimize the business impacts of the incidents. Some companies such as PT. RST and PT. XYZ did not fully implement the incident management and so, the incidents of PT. RST and PT. XYZ' IT services were not fully monitored and controlled well. Therefore, this study aimed to draw up the Standard Operating Procedure (SOP) about incident management for both PT. RST and PT. XYZ, based ITIL 3 version 2011. The data about both companies' existing conditions that was used as the references for drawing up this SOP, gained by online interview to each process owner of both companies. After this SOP had been drawn up, it was verified to each process owner of both companies. In order to the continual improvement, evaluation of this SOP is required based on ITIL 4.
\end{abstract}

Keywords: SOP, Incident Management, Incident, ITIL, IT Services.

\section{Pendahuluan}

Dewasa ini, teknologi informasi (IT) berperan penting bagi keberlangsungan bisnis suatu organisasi, baik sebagai enabler atau bahkan driver bagi bisnis organisasi tersebut. Dengan demikian, IT juga berperan sebagai alat bagi suatu organisasi dalam meraih keunggulan bersaing (competitive advantage) organisasi tersebut [1]. Bagaimanapun produk atau layanan, termasuk layanan berbasis IT (IT services) suatu organisasi dihasilkan melalui serangkaian aktivitas atau proses bisnis dari organisasi tersebut [2]. Organisasi yang berperan sebagai pihak penyedia IT services (IT services provider) harus mampu 
mengelola IT services organisasi tersebut dengan baik karena hal ini sangat berkaitan dengan customer retention atau ketahanan pengguna IT services (pelanggan) organisasi tersebut [1] dan oleh karena itu, Information Technology Service Management (ITSM atau manajemen layanan teknologi informasi) perlu diterapkan atau diadopsi pada organisasi tersebut [3]-[8].

Best practice ITSM yang diterapkan pada berbagai sektor organisasi, termasuk perusahaan di seluruh dunia mengacu pada Information Technology Infrastructure Library (ITIL) [3]-[8]. Saat ini, versi terbaru ITIL yang dirilis ialah ITIL 4 (dirilis pada awal tahun 2019) [8]. Bagaimanapun ITIL terakhir sebelum ITIL 4 dirilis, yakni ITIL 3 versi pembaharuan atau update tahun 2011 (disebut pula sebagai ITIL 3 versi 2011) [3]-[7] belum sepenuhnya tergantikan (masih transisi). Sebagai contoh, PT. RST (suatu perusahaan penyedia layanan pos/ekspedisi di Balikpapan) dan PT. XYZ (suatu perusahaan penyedia layanan berita online di Balikpapan) yang merupakan kasus pada studi ini, masih mengacu pada ITIL versi ini.

Studi ini fokus pada incident management yakni suatu proses pada Bagian Service Operation dalam ITIL 3 yang berkaitan dengan penanganan gangguan (incident) pada IT services agar IT services dapat beroperasi kembali normal (saat IT services tidak mengalami incident) dalam waktu segera (as quickly as possible). Hal ini bertujuan untuk meminimalisir business impact yang ditimbulkan dari incident pada IT services tersebut (dampak finansial dan bahkan dampak reputasi bagi perusahaan yang merupakan penyedia IT services tersebut) [6]. Incident management merupakan salah satu fungsi yang dihandel oleh service desk suatu organisasi sebagai pihak penyedia IT services (IT services provider) selain service request (termasuk complaint handle), yang mana service desk merupakan single-entry point antara pihak IT services provider dengan pihak IT services user/customer [6]. Dengan demikian, implementasi incident management sangat diperlukan bagi organisasi yang merupakan penyedia IT services untuk menjamin kualitas IT services dari organisasi tersebut kepada user (customer) yang menggunakan IT services tersebut, sesuai dengan service level agreement (SLA) antara IT services provider dengan IT services user/customer [4], [6].

Incident pada IT services merupakan [6]:

1. Interupsi tidak terencana (unplanned interruption) pada Configuration Item (CI) pendukung (penunjang) operasional IT services,

2. Degradasi atau penurunan kualitas IT services (sebagai contoh, akses Layanan Sistem Informasi Akademik Universitas XYZ tiba-tiba lambat daripada saat mengakses layanan tersebut sebagaimana biasanya), atau

3. Kegagalan atau malafungsi CI penunjang IT services sehingga berdampak pada kualitas performa IT services tersebut (sebagai contoh, server yang digunakan pada Sistem Service Desk Tickecting PT. XYZ tidak dapat berfungsi karena suatu komponen motherboard server tersebut ada yang hangus diakibatkan ketidakstabilan listrik pada data center yang menjadi lokasi server tersebut sehingga berdampak pada sistem ticketing tersebut tiba bisa diakses sama sekali, disebut sebagai service outage atau unavailability service).

Suatu incident dapat diketahui berdasarkan notifikasi alert dari monitoring tool pada setiap CI penunjang operasional IT services (berkaitan dengan proses event management) dan/atau laporan terkait dari stakeholder (customer/internal business user) [6]. Incident dapat berpotensi menjadi suatu problem apabila incident tersebut terjadi berulang kali dengan simtom yang sama (repetitive incident) atau incident tersebut telah selesai ditangani (resolved incident) tetapi dengan root cause yang tidak jelas (unknown error) [6]. Bagaimanapun incident management fokus mitigation actions dalam rangka meminimalisir business impact yang diakibatkan oleh incident yang terjadi. Bila incident telah menjadi suatu problem, maka hal ini harus ditangani dalam problem management agar fokus pada permanent corrective actions atau permanent fix (permanent resolution) [6].

Beberapa studi atau riset tentang ITSM yang pernah dilakukan/dipublikasikan, terutama adopsi/penerapan incident management atau service desk pada kasus-kasus organisasi seperti [9]-[21]. Bahkan incident management dipandang penting untuk diterapkan pada usaha mikro, kecil, dan menengah (UMKM, termasuk UMKM digital startup) [17], [20]. Namun beberapa organisasi/perusahaan seperti PT. RST dan PT. XYZ yang menjadi kasus studi ini, belum sepenuhnya menerapkan incident management sehingga tidak semua incident yang terjadi pada IT services dari masing-masing perusahaan tersebut terpantau dan terkontrol dengan baik. Hal tersebut terlihat dari dokumentasi yang berkaitan dengan incident management yang belum tersedia pada perusahaan tersebut.

Dengan demikian, studi ini bertujuan untuk menyusun standard operating procedure (SOP) incident management perusahaan (PT. RST dan PT. XYZ) yang mengacu pada best practices ITIL 3 versi 2011. Bagaimanapun SOP inicident management pada PT. RST dan PT. XYZ yang telah disusun, akan dievaluasi kembali sesuai kebutuhan perusahaan, termasuk revisi SOP ini akan mengacu pada best practices ITIL 4. 
Proses penyusunan SOP terkait dalam studi ini dibatasi hingga verifikasi SOP terkait dengan process owner pada masing-masing perusahaan tersebut.

\section{Metode Penelitian}

Mula-mula studi ini dilakukan dengan melakukan studi literatur, yakni kajian teoritis tentang ITIL [3]-[8] dan ditunjang dengan masing-masing kajian teori tentang peran IT dalam keunggulan bersaing perusahaan [1] dan konsep proses bisnis [2], serta kajian pada [9]-[21] yang menjadi landasan dalam merumuskan permasalahan studi ini. Kemudian langkah berikut dalam studi ini ialah pengambilan data dengan melakukan wawancara pada process owner masing-masing perusahaan tersebut yakni Manajer Area Balikpapan PT. RST serta Manajer Bagian IT PT. XYZ secara daring (online) via WhatsApp dan Google Meet karena Pandemi COVID-19. Hal ini dilakukan untuk memperoleh data tentang kondisi terkini pada masing-masing perusahaan tersebut, sebelum menyusun SOP incident management pada masingmasing perusahaan tersebut. Ketika SOP tersebut telah disusun, SOP tersebut diverifikasi dengan process owner pada masing-masing perusahaan tersebut yang menjadi kasus studi ini, sebelum menentukan kesimpulan dari studi ini. Secara singkat, alur keseluruhan studi ini dijabarkan pada Gambar 1.
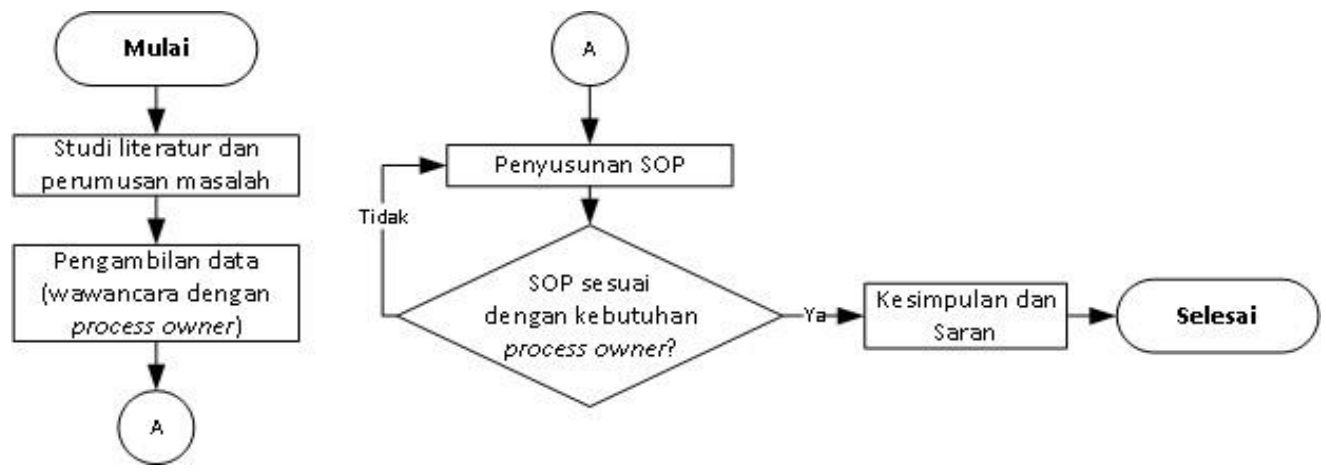

Gambar 1. Alur studi ini.

\section{Hasil dan Pembahasan}

\subsection{Kondisi Terkini Perusahaan}

Kondisi terkini perusahaan dimaksud ialah kondisi terkini saat ini pada PT. RST dan PT. XYZ saat ini, berdasarkan data yang diperoleh melalui wawancara dengan kedua process owner dari masingmasing perusahaan tersebut, meliputi: portofolio IT services, configuration item (CI), serta penanganan incident (incident management) selama ini pada masing-masing perusahaan tersebut. Portofolio IT services yang dimaksud dalam penjelasan bagian ini, ditunjukkan pada masing-masing Tabel 1 dan Tabel 2.

Tabel 1. Portofolio IT services pada PT. RST.

\begin{tabular}{ccl}
\hline Nama IT Service & Digunakan oleh & \multicolumn{1}{c}{ Keterangan IT Service Terkait } \\
\hline Ipos & Bagian Pelayanan & $\begin{array}{l}\text { Digunakan untuk input data customer yang melakukan } \\
\text { pengiriman barang. }\end{array}$ \\
\hline Website RST & Masyarakat & $\begin{array}{l}\text { Digunakan untuk menyampaikan berbagai produk/layanan yang } \\
\text { tersedia di PT. RST. }\end{array}$ \\
\hline $\begin{array}{cc}\text { Sistem Informasi } \\
\text { Keuangan (SIK) }\end{array}$ & Bagian Akuntansi & $\begin{array}{l}\text { Digunakan untuk melakukan pencatatan keuangan yang masuk } \\
\text { dan keluar (cashflow) pada PT. RST. }\end{array}$ \\
\hline SIM SDM & Bagian Dukungan & $\begin{array}{l}\text { Digunakan untuk adminitrasi sumber daya manusia (SDM) PT. } \\
\text { RST. }\end{array}$ \\
\hline U-Pay & Masyarakat & $\begin{array}{l}\text { Digunakan untuk melakukan pembayaran tagihan/angsuran } \\
\text { secara digital. }\end{array}$ \\
\hline E-Pod & Bagian Antaran & $\begin{array}{l}\text { Digunakan untuk pelaporan pengiriman barang kepada penerima } \\
\text { dan E-pod berisi data tentang lokasi, deskriptif penerima barang, } \\
\text { serta tanda tangan bukti penerima barang. }\end{array}$ \\
\hline
\end{tabular}

Tabel 2. Portofolio IT services pada PT. XYZ.

\begin{tabular}{cll}
\hline Nama IT Service & Digunakan oleh & \multicolumn{1}{c}{ Keterangan IT Service Terkait } \\
\hline Sistem Informasi & Bagian Keuangan & $\begin{array}{l}\text { Digunakan untuk manajemen terkait keuangan perusahaan (data } \\
\text { pemasukan dan pengeluaran perusahaan, termasuk laporan } \\
\text { Keuangan (Sibiru) }\end{array}$ \\
& & keuangan perusahaan). \\
\hline
\end{tabular}




\begin{tabular}{cll}
\hline Nama IT Service & Digunakan oleh & \multicolumn{1}{c}{ Keterangan IT Service Terkait } \\
\hline Webmail & $\begin{array}{c}\text { Seluruh Bagian/ } \\
\text { Karyawan }\end{array}$ & $\begin{array}{l}\text { Digunakan oleh karyawan untuk mengakses } e \text {-mail dan bertukar } \\
\text { pesan terkait informasi dan data } \text { - data perusahaan via } e \text {-mail. }\end{array}$ \\
\hline $\begin{array}{c}\text { Sistem Informasi } \\
\text { Iklan (SI Iklan) }\end{array}$ & Bagian Iklan & $\begin{array}{l}\text { Digunakan untuk manajemen kegiatan operasional terkait } \\
\text { transaksi pemasangan iklan di PT. XYZ. }\end{array}$ \\
\hline $\begin{array}{c}\text { Sistem Informasi } \\
\text { Human Resource }\end{array}$ & $\begin{array}{c}\text { Seluruh Bagian/ } \\
\text { Keneral Affair }(\mathrm{SI}\end{array}$ & Digunakan untuk manajemen data karyawan perusahaan. \\
HRGA) & Masyanakat dan & $\begin{array}{l}\text { Digunakan untuk manajemen proses layanan berita, iklan, } \\
\text { televisi, dan radio online kepada masyarakat. }\end{array}$ \\
\hline Website XYZ & Bagian Redaksi &
\end{tabular}

CI yang dimaksud dalam penjelasan bagian ini fokus pada server yang digunakan oleh IT services dari masing-masing IT services provider kedua perusahaan tersebut, ditunjukkan pada Tabel 3 dan Tabel 4.

Tabel 3. CI (server) dari IT services pada PT. RST.

\begin{tabular}{ccc}
\hline Nama IT Service & Primary Server & Backup Server \\
\hline Ipos & Server Nasional (Bandung) & Server Lokal Balikpapan \\
\hline Website RST & Server Nasional (Bandung) & Server Lokal Balikpapan \\
\hline SIK & Server Lokal Balikpapan & - \\
\hline SIM SDM & Server Lokal Balikpapan & - \\
\hline E-Pay & Server C2A Prima (Jakarta) & - \\
\hline E-Pod & Server Lokal Balikpapan & - \\
\hline
\end{tabular}

Tabel 4. CI (server) dari IT services pada PT. XYZ.

\begin{tabular}{ccc}
\hline Nama IT Service & Primary Server & Backup Server \\
\hline Sibiru & Server JSI Surabaya & Server JSI Balikpapan \\
\hline Webmail & Server E-mail Balikpapan & - \\
\hline SI Iklan & Server JSI Surabaya & Server JSI Balikpapan \\
\hline SI HRGA & Server JSI Surabaya & Server JSI Balikpapan \\
\hline Website XYZ & Server XYZ Balikpapan 01 & Server XYZ Balikpapan 02 \\
\hline
\end{tabular}

Penanganan incident (incident management) yang diterapkan selama ini pada PT. RST dan PT. XYZ, dijelaskan secara rinci pada Tabel 5.

Tabel 5. Kondisi incident management secara terkini pada PT. RST dan PT. XYZ.

\begin{tabular}{|c|c|c|}
\hline $\begin{array}{c}\text { Tahapan } \\
\text { Incident } \\
\text { Management }\end{array}$ & $\begin{array}{c}\text { Penerapan Incident Management } \\
\text { Terkini di PT. RST }\end{array}$ & $\begin{array}{c}\text { Penerapan Incident Management Terkini } \\
\text { di PT. XYZ }\end{array}$ \\
\hline $\begin{array}{l}\text { Incident } \\
\text { Identification }\end{array}$ & $\begin{array}{l}\text { Incident diidentifikasi setelah menerima } \\
\text { laporan dari user berdasarkan pemikiran } \\
\text { dari Bagian Solusi dan Teknologi } \\
\text { (SOLTEK). }\end{array}$ & $\begin{array}{l}\text { Laporan incident dari user diidentifikasi } \\
\text { melalui telepon. }\end{array}$ \\
\hline Incident Logging & $\begin{array}{l}\text { Incident yang telah dilaporkan oleh } \text { user } \\
\text { tidak dilakukan pencatatan. }\end{array}$ & $\begin{array}{l}\text { Pencatatan incident yang masuk, baik secara } \\
\text { manual maupun melalui sistem/aplikasi } \\
\text { terkait belum dilakukan. }\end{array}$ \\
\hline $\begin{array}{c}\text { Incident } \\
\text { Categorization }\end{array}$ & $\begin{array}{l}\text { Tidak adanya panduan terkait ketentuan } \\
\text { dalam menentukan kategorisasi dari } \\
\text { masing-masing incident yang telah } \\
\text { dilaporkan oleh } \text { user. }\end{array}$ & $\begin{array}{l}\text { Belum membuat kategori incident serta } \\
\text { incident belum ditangani berdasarkan } \\
\text { kategori sebagaimana mestinya. }\end{array}$ \\
\hline $\begin{array}{c}\text { Incident } \\
\text { Prioritization }\end{array}$ & $\begin{array}{l}\text { Tidak terdapat prioritas untuk masing- } \\
\text { masing incident yang sesuai dengan } \\
\text { penilaian incident prioritization sesuai } \\
\text { best practices ITIL. }\end{array}$ & $\begin{array}{l}\text { Penanganan incident tidak diprioritaskan } \\
\text { karena prioritas incident belum dibuat. }\end{array}$ \\
\hline $\begin{array}{c}\text { Incident } \\
\text { Diagnosis }\end{array}$ & $\begin{array}{l}\text { Penyebeb terjadinya incident diketahui } \\
\text { berdasarkan pengetahuan dan } \\
\text { pengalaman atau analisis berdasarkan } \\
\text { informasi yang disampaikan oleh } \text { user. }\end{array}$ & $\begin{array}{l}\text { Penyebab incident dicari berdasarkan } \\
\text { pengetahuan dan pengalaman dari karyawan } \\
\text { bagian IT namun dokumentasi terkait dari } \\
\text { kegiatan diagnosis awal incident belum } \\
\text { dilakukan. }\end{array}$ \\
\hline $\begin{array}{c}\text { Incident } \\
\text { Escalation }\end{array}$ & $\begin{array}{l}\text { Jika terjadi incident terkait IT services } \\
\text { maka hal tersebut ditangani oleh Bagian } \\
\text { SOLTEK. Namun, jika terjadi incident } \\
\text { terkait server maka hal tersebut ditangani } \\
\text { oleh Manajer Sarana dan Teknologi. }\end{array}$ & $\begin{array}{l}\text { Penanganan incident dilakukan oleh bagian } \\
\text { IT, tetapi jika tidak dapat ditangani oleh } \\
\text { bagian IT maka proses eskalasi akan } \\
\text { langsung diteruskan ke pihak ketiga (third } \\
\text { party) atau vendor. }\end{array}$ \\
\hline
\end{tabular}




\begin{tabular}{|c|c|c|}
\hline $\begin{array}{c}\text { Tahapan } \\
\text { Incident } \\
\text { Management } \\
\end{array}$ & $\begin{array}{c}\text { Penerapan Incident Management } \\
\text { Terkini di PT. RST }\end{array}$ & $\begin{array}{c}\text { Penerapan Incident Management Terkini } \\
\text { di PT. XYZ }\end{array}$ \\
\hline $\begin{array}{l}\text { Investigation \& } \\
\text { Diagnosis }\end{array}$ & $\begin{array}{l}\text { Memahami incident berdasarkan } \\
\text { pemahaman/ pengetahuan dari Bagian } \\
\text { SOLTEK atau datang secara langsung } \\
\text { untuk melakukan pemeriksaan secara } \\
\text { fisik. }\end{array}$ & $\begin{array}{l}\text { Proses investigasi dan diagnosis incident } \\
\text { yang terjadi pada IT services telah dilakukan } \\
\text { oleh Bagian IT, tetapi kegiatan tersebut } \\
\text { belum pernah terdokumentasikan. }\end{array}$ \\
\hline $\begin{array}{l}\text { Resolution \& } \\
\text { Recovery }\end{array}$ & $\begin{array}{l}\text { Penyelesaian incident dilakukan secara } \\
\text { langsung dengan mendatangi secara fisik } \\
\text { maupun melakukan pemanduan } \\
\text { menggunakan jaringan komunikasi. }\end{array}$ & $\begin{array}{l}\text { Penyelesaian incident masih hanya terbatas } \\
\text { pada pengetahuan dan pengalaman tim IT, } \\
\text { belum berdasarkan prosedur terstandarisasi } \\
\text { yang mengacu pada ITIL. Selain itu, belum } \\
\text { ada dokumentasi terkait incident } \\
\text { management pada tahap ini. }\end{array}$ \\
\hline Incident Closure & $\begin{array}{l}\text { Penutupan incident dilakukan dengan } \\
\text { menguhubungi pelapor ( user) bahwa } \\
\text { incident telah terselesaikan. Namun } \\
\text { aktivitas permintaan feedback dari user } \\
\text { atas penanganan incident yang telah } \\
\text { dilakukan belum ada. }\end{array}$ & $\begin{array}{l}\text { Penutupan penanganan incident dilaporkan } \\
\text { kembali kepada pengguna, tetapi belum ada } \\
\text { pencatatan dan dokumentasi terkait } \\
\text { penutupan penanganan incident. Selain itu, } \\
\text { survei kepuasaan } \text { user (customer) juga belum } \\
\text { dilakukan. }\end{array}$ \\
\hline
\end{tabular}

Penanganan incident secara terkini pada masing-masing PT. RST dan PT. XYZ seperti dijabarkan pada Tabel 5, belum dilakukan sesuai dengan best practices ITIL sehingga penyusunan SOP terkait yang mengacu pada best practices ITIL untuk masing-masing perusahaan tersebut memang dibutuhkan. Kelengkapan terkait penyusunan SOP yang dimaksud, dijabarkan secara rinci pada Tabel 6.

Tabel 6. Kelengkapan penyusunan SOP penanganan incident (incident management).

\begin{tabular}{|c|c|}
\hline Kelengkapan & Keterangan \\
\hline $\begin{array}{c}\text { Prosedur } \\
\text { Pencatatan Incident }\end{array}$ & $\begin{array}{l}\text { Digunakan untuk melakukan pencatatan incident berdasarkan notifikasi incident dari alert atau } \\
\text { laporan stakeholder. }\end{array}$ \\
\hline $\begin{array}{c}\text { Formulir } \\
\text { Pencatatan Incident }\end{array}$ & $\begin{array}{l}\text { Sebagai bukti laporan incident yang masuk dan proses penanganan incident terkait yang telah } \\
\text { dilakukan oleh service desk. }\end{array}$ \\
\hline $\begin{array}{l}\text { Prosedur } \\
\text { Penanganan } \\
\text { Incident }\end{array}$ & $\begin{array}{l}\text { Apabila incident yang terjadi dilaporkan oleh user kepada service desk dari IT services provider } \\
\text { maka prosedur ini digunakan, mulai dari proses kategorisasi hingga penanganan dan penyelesaian } \\
\text { incident tersebut. }\end{array}$ \\
\hline $\begin{array}{l}\text { Formulir Eskalasi } \\
\text { Incident }\end{array}$ & $\begin{array}{l}\text { Sebagai bukti eskalasi dalam proses penanganan incident oleh service desk apabila incident tersebut } \\
\text { tidak dapat tertangani sendiri oleh service desk. Misalnya, penanganan incident perlu melibatkan } \\
\text { pihak lain seperti engineer pada bagian IT tertentu (database, aplikasi, atau jaringan, tergantung } \\
\text { kasus incident tersebut), bahkan hingga melibatkan pihak ketiga atau vendor pada kasus incident } \\
\text { tertentu. }\end{array}$ \\
\hline $\begin{array}{l}\text { Prosedur } \\
\text { Penutupan Incident } \\
\text { (Incident Closure) }\end{array}$ & $\begin{array}{l}\text { Digunakan untuk melakukan proses penutupan incident yang telah selesai ditangani atau incident } \\
\text { yang terpaksa ditutup karena incident tersebut tidak dapat diselesaikan dalam incident management } \\
\text { (incident tersebut berubah menjadi problem dan harus ditangani dalam problem management dalam } \\
\text { rangka permanent resolution [6]). }\end{array}$ \\
\hline $\begin{array}{l}\text { Formulir Survei } \\
\text { Kepuasan User } \\
\quad \text { (Customer) }\end{array}$ & $\begin{array}{l}\text { Sebagai bukti kepuasan user/customer terhadap penanganan oleh service desk (secara khusus, } \\
\text { penanganan incident pada IT services) dan hal ini juga menjadi bahan/referensi untuk melakukan } \\
\text { peningkatan layanan (continual service improvement) kepada user/ customer yang menggunakan IT } \\
\text { services dari IT services provider (PT. RST dan PT. XYZ) [6], [7]. }\end{array}$ \\
\hline Incident Report & $\begin{array}{l}\text { Dokumen yang berisi dokumentasi penanganan incident seperti incident priority, rentang waktu } \\
\text { incident terjadi (termasuk waktu incident pertama kali terjadi hingga waktu incident telah selesai } \\
\text { tertangani/incident resolved), kronologi incident, analisis penyebab incident terjadi (incident root } \\
\text { cause analysis atau RCA), serta mitigation actions dari incident terkait. }\end{array}$ \\
\hline
\end{tabular}

\subsection{Penyusunan SOP Incident Management}

Dengan pertimbangan kondisi penanganan incident pada PT. RST dan PT. XYZ seperti dijabarkan pada Tabel 5, jika mengacu pada best practices ITIL pada bagian incident management [6] maka SOP incident management untuk masing-masing perusahaan tersebut disusun seperti ditunjukkan pada Gambar 2, Gambar 3, dan Gambar 4. Penyusunan SOP tersebut juga disesuaikan dengan kelengkapan terkait seperti ditunjukkan pada Tabel 6. Penyusunan SOP incident management pada PT. RST dan PT. XYZ juga berkaitan dengan proses penentuan incident priority pada incident yang tercatat sebagaimana dimaksud pada Gambar 3 tentang proses penentuan incident priority dan hal ini dijelaskan secara lebih rinci pada Sub Bab 3.3 tentang penentuan incident priority. 

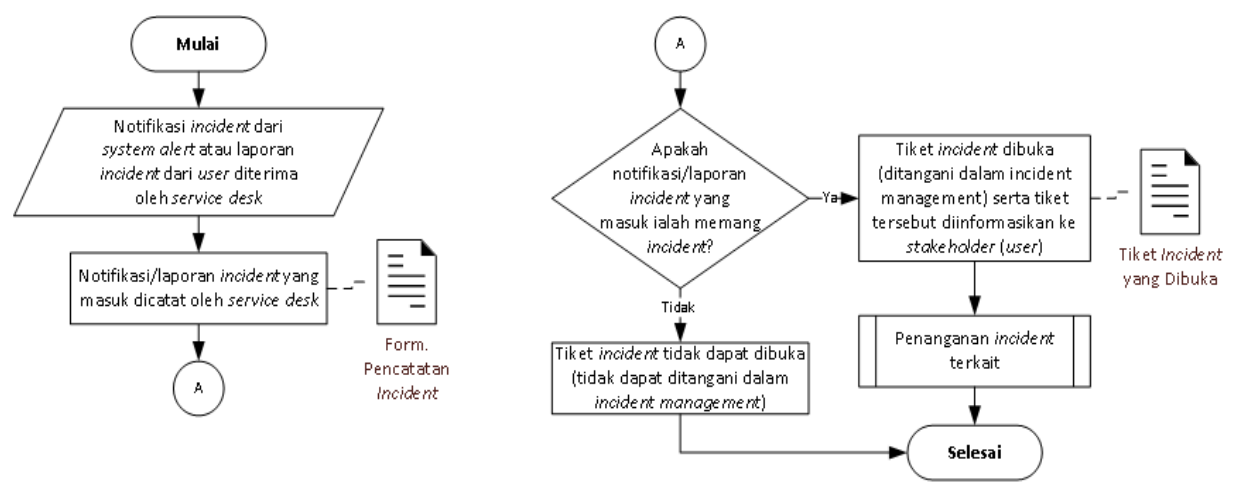

Gambar 2. SOP incident management untuk PT. RST dan PT. XYZ.

Berdasarkan skema incident prioritization (penentuan incident priority), incident terbagi atas major incident dan minor incident [6]. Suatu incident disebut major incident bilamana incident tersebut telah menimbulkan dampak bisnis (business impacts) bagi perusahaan yang merupakan IT services provider dan sebaliknya, minor incident belum menimbulkan business impacts (hanya berdampak secara teknis atau operational impacts) [6]. Dengan demikian, proses penanganan incident pada major incident agak berbeda dengan minor incident seperti proses penanganan incident yang kerap melibatkan forum (meeting) dan bahkan berujung eskalasi pada layer 2 (L2) atau hingga layer 3 (L3) pada kasus incident tertentu [6]. Proses penanganan incident pada major incident juga tidak jarang melibatkan emergency change management processes (misalnya incident dengan incident priority ialah P2 atau bahkan P1) [5], [6]. Pada prosedur pasca penanganan incident atau penutupan tiket incident (ditunjukkan pada Gambar 4 pada kasus studi ini), incident yang merupakan major incident wajib dibuatkan Dokumen Incident Report sebagai referensi bagi service desk jika incident tersebut berpotensi menjadi problem pada waktu mendatang (Incident Report bersifat opsional bagi incident yang merupakan minor incident).
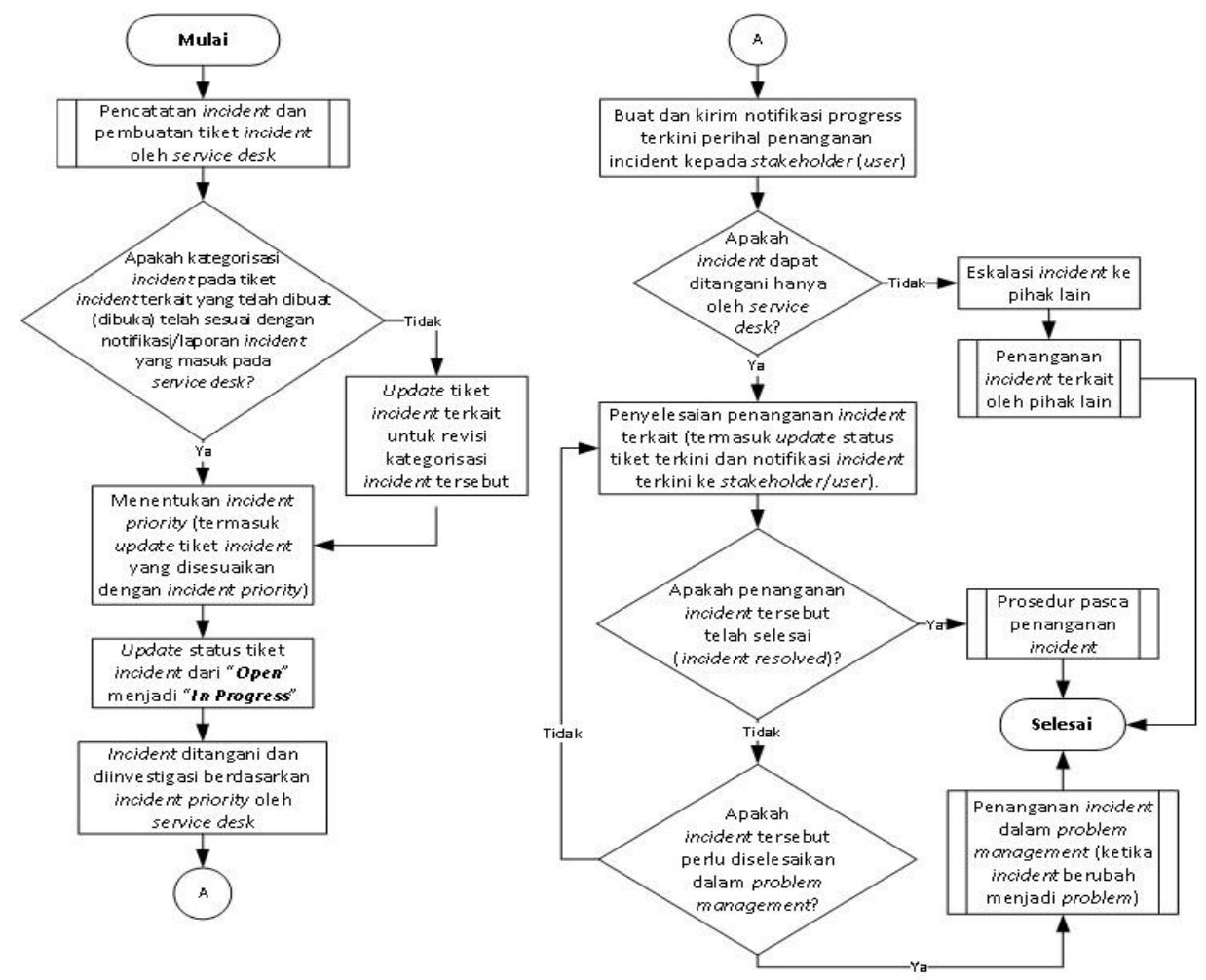

Gambar 3. Detail prosedur penanganan incident.

Service desk merupakan layer pertama (L1) dalam proses penanganan incident dan bila incident tidak dapat ditangani sendiri oleh service desk, maka eskalasi dalam proses penanganan incident perlu 
dilakukan (ditunjukkan pada Gambar 3) baik pada L2 dan pada kasus incident tertentu, bahkan hingga L3 [22]. Pada PT. RST, Bagian SOLTEK merupakan L2 serta perusahaan yang bekerja sama dengan PT. RST sebagai vendor (termasuk perusahaan penyedia layanan dan infrastruktur telekomunikasi/IT seperti Telkom dan Lintasarta) merupakan L3. Pada PT. XYZ, IT engineer (sesuai bidang IT terkait, misalnya network engineer, database engineer, dan programmer) merupakan L2 serta tim IT dari perusahaan induk yang menaungi PT. XYZ dan perusahaan yang bekerja sama dengan PT. XYZ seperti Telkom, Transcom, dan Lintasarta merupakan L3.
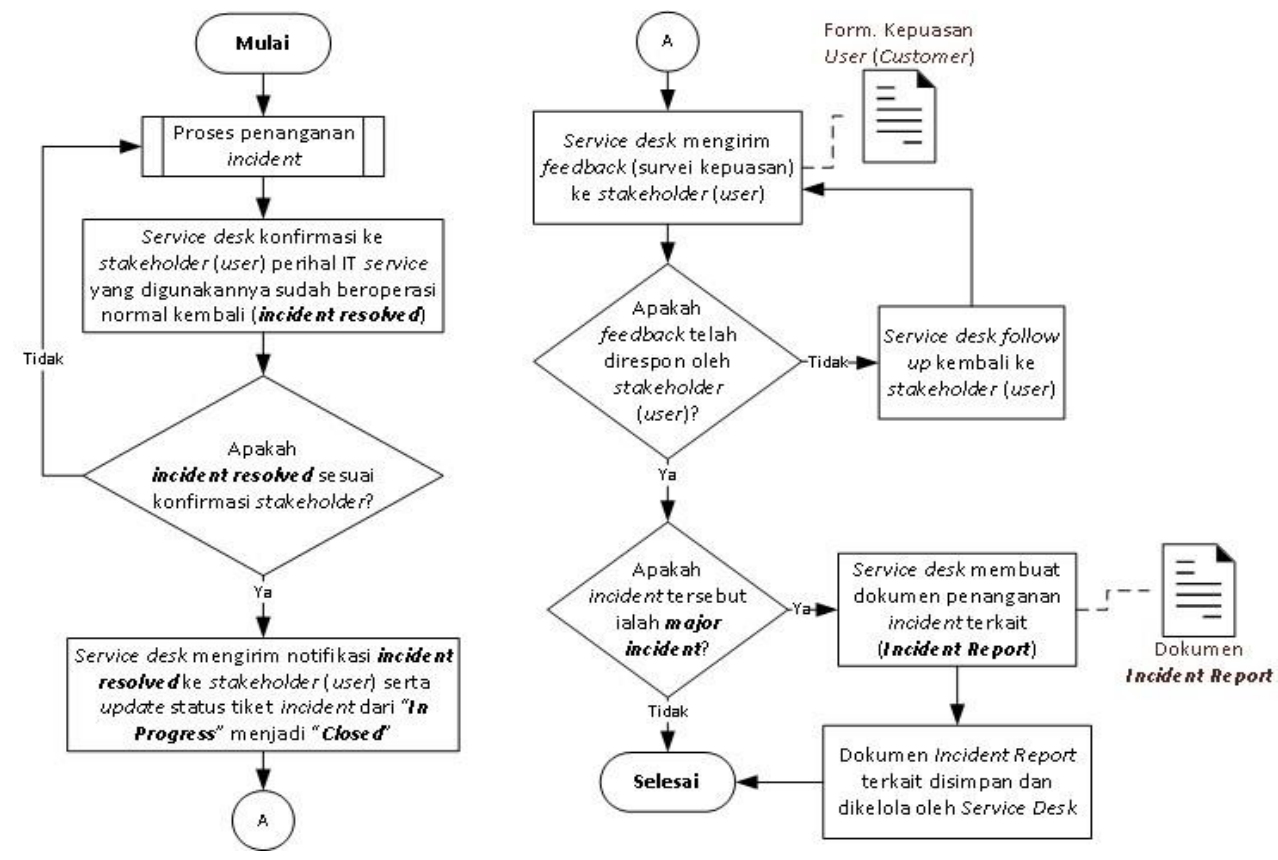

Gambar 4. Detail prosedur pasca penanganan incident (incident ticket closure).

Berdasarkan Model RACI dalam incident management, stakeholder (customer/organizational internal business user) merupakan pihak yang harus diinformasikan (Informed Role) terkait progres penanganan incident selama incident terjadi (mulai dari awal waktu incident terjadi, mitigation actions pada incident terkait, hingga incident dinyatakan resolved dan tiket incident terkait ditutup) [23]. Oleh karena itu, service desk memang berkewajiban membuat notifikasi incident berupa informasi tentang progres penanganan incident dan menyampaikannya kepada stakeholder. Penyampaian notifikasi terkait dapat dilakukan oleh service desk kepada stakeholder melalui e-mail dan/atau SMS broadcast.

SOP incident management yang telah disusun untuk PT. RST dan PT. XYZ, telah diverifikasi dengan process owner pada masing-masing perusahaan tersebut yang bertujuan untuk mencocokkan kesesuaian SOP ini dengan kebutuhan masing-masing perusahaan tersebut. Proses verifikasi SOP ini dengan process owner pada masing-masing perusahaan tersebut dilakukan secara online. Secara umum, SOP ini diterima/disetujui oleh process owner pada masing-masing perusahaan tersebut walaupun SOP ini akan dievaluasi kembali sesuai kebutuhan perusahaan pada masa mendatang dalam rangka continual improvement [7], [8].

\subsection{Penentuan Incident Priority}

Mengacu pada penentuan incident priority dalam best practice ITIL (ITIL 3 versi 2011) [6], incident priority pada suatu incident, seperti ditunjukkan pada Tabel 11 dalam studi ini, ditentukan oleh impact level dan urgency level. Impact level merupakan dampak bisnis (business impacts) yang diakibatkan oleh incident pada IT services yang ditanggung oleh IT services provider (PT. RST dan PT. XYZ untuk kasus studi ini) [6] dan pada studi ini, impact level yang dimaksud ditunjukkan pada Tabel 7 dan Tabel 8.

Tabel 7. Impact level dari incident pada IT services PT. RST.

\begin{tabular}{ccl}
\hline Nama IT Service & Impact Level & \multicolumn{1}{c}{ Keterangan } \\
\hline Ipos & High & Bila IT service ini mengalami incident selama beberapa jam maka hal \\
& & tersebut berdampak signifikan pada proses bisnis pengiriman paket dan \\
& surat di PT. RST (operasional Bagian Pelayanan Surat dan Paket terhambat
\end{tabular}




\begin{tabular}{|c|c|c|}
\hline Nama IT Service & Impact Level & Keterangan \\
\hline & & $\begin{array}{l}\text { dalam melakukan input data pengiriman paket dan surat akibat incident } \\
\text { pada IT service ini). }\end{array}$ \\
\hline Website RST & High & $\begin{array}{l}\text { Bila IT service ini mengalami incident, maka hal tersebut berdampak secara } \\
\text { signifikan pada proses bisnis utama PT. RST. Dalam hal ini, customer PT. } \\
\text { RST mengalami kesulitan dalam mengakses informasi produk/layanan PT. } \\
\text { RST dan bahkan } \text { customer tidak dapat menikmati layanan tertentu dari PT. } \\
\text { RST seperti tracking pengiriman paket atau dokumen/surat. }\end{array}$ \\
\hline SIK & Medium & $\begin{array}{l}\text { Apabila SIK mengalami incident yang berdampak pada akses IT service ini } \\
\text { oleh Bagian Akuntansi maka bagian ini dapat melakukan solusi alternatif } \\
\text { lain yakni melakukan pelaporan ataupun pencatatan keuangan yang masuk } \\
\text { dan keluar dengan menggunakan email dan/atau paper. }\end{array}$ \\
\hline SIM SDM & Medium & $\begin{array}{l}\text { Apabila SIM SDM mengalami incident sehingga berdampak pada akses IT } \\
\text { service ini oleh Bagian Dukungan Umum, maka bagian ini dapat } \\
\text { melakukan solusi alternatif lain yakni dengan melakukan administrasi } \\
\text { SDM secara manual dengan menuliskan ke dalam buku SDM untuk } \\
\text { sementara waktu. }\end{array}$ \\
\hline E-Pay & High & $\begin{array}{l}\text { Bila E-Pay mengalami incident yang berakibat pada kendala akses IT } \\
\text { service maka hal tersebut berdampak signifikan pada proses bisnis layanan } \\
\text { pembayaran tagihan/angsuran pada PT. RST (customer PT. RST tidak } \\
\text { dapat melakukan pembayaran tagihan/angsuran melalui IT service ini } \\
\text { sehingga hal tersebut berpotensi menimbulkan kerugian secara finansial } \\
\text { dan reputasi pada PT. RST). }\end{array}$ \\
\hline E-Pod & Medium & $\begin{array}{l}\text { Apabila E-Pod mengalami incident yang berakibat pada input dalam } \\
\text { pelaporan penerimaan barang tidak dapat dilakukan melalui IT service ini, } \\
\text { maka Bagian Antaran dapat melakukan solusi alternatif lain yaitu dengan } \\
\text { mengisi suatu form yang disebut Form R7. }\end{array}$ \\
\hline
\end{tabular}

Tabel 8. Impact level dari incident pada IT services PT. XYZ.

\begin{tabular}{|c|c|c|}
\hline Nama IT Service & Impact Level & Keterangan \\
\hline Sibiru & High & $\begin{array}{l}\text { Bila IT service ini mengalami incident, maka hal tersebut berdampak pada } \\
\text { kesalahan dalam pengambilan keputusan mengenai kondisi keuangan. } \\
\text { Proses transaksi keuangan (pengeluaran dan pemasukan perusahaan) } \\
\text { seperti penggajian karyawan dan pembayaran kepada vendor yang bekerja } \\
\text { sama dengan PT. XYZ akan bermasalah. }\end{array}$ \\
\hline Webmail & Medium & $\begin{array}{l}\text { Bila IT service ini mengalami incident, maka hal tersebut berdampak pada } \\
\text { proses pertukaran informasi dan data perusahaan melalui layanan e-mail } \\
\text { perusahaan. Namun bila incident tersebut terjadi, maka perusahaan } \\
\text { memiliki beberapa rencana seperti: } \\
\text { - Penggunaan sosial media dan e-mail pribadi karyawan sebagai media } \\
\text { komunikasi sementara antar karyawan perusahaan. } \\
\text { - Backup secara berkala untuk setiap user pada e-mail perusahaan. }\end{array}$ \\
\hline SI Iklan & High & $\begin{array}{l}\text { Bila IT service ini mengalami incident, maka hal tersebut berdampak } \\
\text { signifikan pada proses transaksi terkait pemasangan iklan sehingga hal } \\
\text { tersebut juga berdampak negatif pada kerja sama antara stakeholder } \\
\text { (client/customer) dengan PT. XYZ yang menyediakan layanan pemasangan } \\
\text { iklan. Dengan kata lain, incident pada IT service ini berdampak pada } \\
\text { reputasi PT. XYZ (risiko reputasi) sehingga secara tidak langsung, hal } \\
\text { tersebut juga berdampak pada revenue PT. XYZ yang berasal dari layanan } \\
\text { pemasangan iklan (risiko finansial). }\end{array}$ \\
\hline SI HRGA & High & $\begin{array}{l}\text { Bila IT service ini mengalami incident, maka hal tersebut berdampak pada } \\
\text { gangguan akses atau penggunaan data karyawan PT. XYZ (misalnya, } \\
\text { penggunaan data absen karyawan terkait penggaiian dan cuti karyawan). }\end{array}$ \\
\hline Website XYZ & High & $\begin{array}{l}\text { IT service ini merupakan core service pada PT. XYZ. Dengan demikian, } \\
\text { bila IT service ini mengalami incident, maka hal tersebut berdampak } \\
\text { signifikan pada keberlangsungan proses bisnis utama PT. XYZ. }\end{array}$ \\
\hline
\end{tabular}

CI merupakan komponen pendukung/penunjang operasional IT service (contohnya ialah masingmasing server, aplikasi, dan database pada Sibiru sebagai suatu IT service pada PT. XYZ) [4] dan kualitas performa (kinerja) CI turut memengaruhi kualitas dari IT service yang operasionalnya ditunjang dari CI tersebut. Dengan demikian, bila CI pada IT service semakin critical maka hal ini turut menentukan urgency level pada CI dalam rangka menentukan incident priority, seperti ditunjukkan pada Tabel 9 dan Tabel 10.

Tabel 9. Urgency level pada masing-masing CI PT. RST.

\begin{tabular}{cccc}
\hline Nama CI & $\begin{array}{c}\text { IT Service } \\
\text { Terkait }\end{array}$ & $\begin{array}{c}\text { Urgency } \\
\text { Level }\end{array}$ & Keterangan \\
\hline Server Nasional & Ipos dan & Medium & Ipos dan Website RST juga menggunakan Server Lokal \\
& Website RST & & Balikpapan dalam operasionalnya sebagai backup server \\
\hline
\end{tabular}

Penyusunan SOP Incident Management pada PT. RST dan PT. XYZ Berdasarkan ITIL 3 Versi 2011

(I Putu Deny Arthawan Sugih Prabowo) 


\begin{tabular}{|c|c|c|c|}
\hline Nama CI & $\begin{array}{c}\text { IT Service } \\
\text { Terkait }\end{array}$ & $\begin{array}{c}\text { Urgency } \\
\text { Level }\end{array}$ & Keterangan \\
\hline & & & $\begin{array}{l}\text { apabila Server Nasional sebagai server utamanya } \\
\text { (primary server) mengalami incident (bahkan pada saat } \\
\text { Server Nasional tidak berfungsi sama sekali atau kondisi } \\
\text { ini juga diketahui sebagai service outagelunavailability } \\
\text { service). }\end{array}$ \\
\hline $\begin{array}{l}\text { Masing-masing } \\
\text { aplikasi terkait } \\
\text { Ipos dan } \\
\text { Website RST }\end{array}$ & $\begin{array}{c}\text { Ipos dan } \\
\text { Website RST }\end{array}$ & Medium & $\begin{array}{l}\text { - CI ini yang dimaksud ialah aplikasi terkait Ipos dan } \\
\text { aplikasi terkait Website RST (bukan satu aplikasi yang } \\
\text { digunakan oleh kedua IT service ini sekaligus). } \\
\text { - Masing-masing aplikasi tersebut berjalan pada Server } \\
\text { Nasional (primary server) dan Server Lokal Balikpapan } \\
\text { (backup server). Apabila masing-masing aplikasi } \\
\text { tersebut pada Server Nasional mengalami incident, } \\
\text { maka hal ini tidak berdampak signifikan pada } \\
\text { operasional Ipos dan Website RST karena masing- } \\
\text { masing aplikasi tersebut juga masih berjalan baik pada } \\
\text { Server Lokal Balikpapan (kecuali masing-masing } \\
\text { aplikasi tersebut pada Server Lokal Balikpapan dan/atau } \\
\text { Server Lokal Balikpapan juga mengalami incident). }\end{array}$ \\
\hline $\begin{array}{l}\text { Masing-masing } \\
\text { database terkait } \\
\text { Ipos dan } \\
\text { Website RST }\end{array}$ & $\begin{array}{c}\text { Ipos dan } \\
\text { Website RST }\end{array}$ & Medium & $\begin{array}{l}\text { - CI ini yang dimaksud ialah database terkait Ipos dan } \\
\text { database terkait Website RST. } \\
\text { - Masing-masing database tersebut berjalan pada Server } \\
\text { Nasional dan Server Lokal Balikpapan. Apabila } \\
\text { masing-masing database tersebut pada Server Nasional } \\
\text { mengalami incident, maka hal ini tidak berdampak } \\
\text { signifikan pada operasional Ipos dan Website RST } \\
\text { karena masing-masing database tersebut juga masih } \\
\text { berjalan baik pada Server Lokal Balikpapan (kecuali } \\
\text { masing-masing database tersebut pada Server Lokal } \\
\text { Balikpapan dan/atau Server Lokal Balikpapan juga } \\
\text { mengalami incident). }\end{array}$ \\
\hline $\begin{array}{c}\text { Server Lokal } \\
\text { Balikpapan }\end{array}$ & $\begin{array}{l}\text { - } \text { SIK, SIM } \\
\text { SDM, dan E- } \\
\text { Pod (primary } \\
\text { server). } \\
\text { - Ipos dan } \\
\text { Website } \text { RST } \\
\text { (backup } \\
\text { server). }\end{array}$ & High & $\begin{array}{l}\text { Walaupun Server Lokal Balikpapan juga berfungsi } \\
\text { sebagai backup server bagi Ipos dan Website RST, tetapi } \\
\text { server ini merupakan server utama bagi SIK, SIM SDM, } \\
\text { dan E-Pod dan IT services tersebut hanya berjalan pada } \\
\text { Server Lokal Balikpapan (tidak ada server lain yang } \\
\text { berfungsi sebagai backup bagi operasional SIK, SIM } \\
\text { SDM, dan E-Pod). }\end{array}$ \\
\hline $\begin{array}{l}\text { Masing-masing } \\
\text { aplikasi terkait } \\
\text { SIK, SIM SDM, } \\
\text { dan E-Pod }\end{array}$ & $\begin{array}{l}\text { SIK, SIM SDM, } \\
\quad \text { dan E-Pod }\end{array}$ & High & $\begin{array}{l}\text { Aplikasi terkait SIK, aplikasi terkait SIM SDM, dan } \\
\text { aplikasi terkait E-Pod hanya berjalan/menggunakan } \\
\text { Server Lokal Balikpapan sehingga hal ini menjadi riskan } \\
\text { apabila masing-masing aplikasi tersebut mengalami } \\
\text { incident. }\end{array}$ \\
\hline $\begin{array}{l}\text { Masing-masing } \\
\text { database terkait } \\
\text { SIK, SIM SDM, } \\
\text { dan E-Pod }\end{array}$ & $\begin{array}{l}\text { SIK, SIM SDM, } \\
\quad \text { dan E-Pod }\end{array}$ & High & $\begin{array}{l}\text { Database terkait SIK, database terkait SIM SDM, dan } \\
\text { database terkait E-Pod hanya menggunakan Server Lokal } \\
\text { Balikpapan sehingga hal ini menjadi riskan apabila } \\
\text { masing-masing database tersebut mengalami incident. }\end{array}$ \\
\hline $\begin{array}{l}\text { Server C2A } \\
\text { Prima }\end{array}$ & E-Pay & High & $\begin{array}{l}\text { E-Pay hanya berjalan pada Server C2A Prima (tidak ada } \\
\text { backup server yang digunakan oleh IT service ini } \\
\text { sehingga kondisi ini menjadi riskan apabila Server } \mathrm{C} 2 \mathrm{~A} \\
\text { Prima mengalami incident). }\end{array}$ \\
\hline $\begin{array}{c}\text { Aplikasi terkait } \\
\text { E-Pay }\end{array}$ & E-Pay & High & $\begin{array}{l}\text { Aplikasi terkait E-Pay hanya berjalan pada Server } \mathrm{C} 2 \mathrm{~A} \\
\text { Prima sehingga kondisi ini menjadi riskan apabila aplikasi } \\
\text { tersebut mengalami incident. }\end{array}$ \\
\hline $\begin{array}{c}\text { Database terkait } \\
\text { E-Pay }\end{array}$ & E-Pay & High & $\begin{array}{l}\text { Database terkait E-Pay hanya menggunakan Server } \mathrm{C} 2 \mathrm{~A} \\
\text { Prima sehingga kondisi ini menjadi riskan apabila } \\
\text { database tersebut mengalami incident. }\end{array}$ \\
\hline
\end{tabular}

Tabel 10. Urgency level pada masing-masing CI PT. XYZ.

\begin{tabular}{|c|c|c|c|}
\hline Nama CI & $\begin{array}{c}\text { IT Service } \\
\text { Terkait }\end{array}$ & $\begin{array}{c}\text { Urgency } \\
\text { Level }\end{array}$ & Keterangan \\
\hline $\begin{array}{l}\text { Server JSI } \\
\text { Surabaya }\end{array}$ & $\begin{array}{l}\text { Sibiru, SI Iklan, } \\
\text { dan SI HRGA }\end{array}$ & Medium & $\begin{array}{l}\text { Jika Server JSI Surabaya yang digunakan oleh operasional } \\
\text { Sibiru, SI Iklan, dan SI HRGA mengalami incident, maka hal } \\
\text { ini tidak berdampak signifikan pada operasional Sibiru, SI } \\
\text { Iklan, dan SI HRGA ketika Server JSI Balikpapan masih dapat } \\
\text { difungsikan sebagai backup. }\end{array}$ \\
\hline $\begin{array}{l}\text { Server JSI } \\
\text { Balikpapan }\end{array}$ & $\begin{array}{l}\text { Sibiru, SI Iklan, } \\
\text { dan SI HRGA }\end{array}$ & Medium & $\begin{array}{l}\text { Server JSI Balikpapan merupakan server yang difungsikan } \\
\text { sebagai backup dalam mendukung operasional Sibiru, SI Iklan, }\end{array}$ \\
\hline
\end{tabular}




\begin{tabular}{|c|c|c|c|}
\hline & & & $\begin{array}{l}\text { dan SI HRGA jika Server JSI Surabaya mengalami incident. } \\
\text { Server JSI Balikpapan juga tidak terletak pada data center yang } \\
\text { sama dengan Server JSI Surabaya, bila mengacu "rule of } \\
\text { thumb" penempatan server dalam Disaster Recovery Plan } \\
\text { (DRP) [24], [25]. }\end{array}$ \\
\hline $\begin{array}{l}\text { Masing- } \\
\text { masing } \\
\text { aplikasi } \\
\text { terkait } \\
\text { Sibiru, SI } \\
\text { Iklan, dan SI } \\
\text { HRGA }\end{array}$ & $\begin{array}{l}\text { Sibiru, SI Iklan, } \\
\text { dan SI HRGA }\end{array}$ & Medium & $\begin{array}{l}\text { Aplikasi terkait Sibiru, aplikasi terkait SI Iklan, dan aplikasi } \\
\text { terkait SI HRGA berjalan pada Server JSI Surabaya dan Server } \\
\text { JSI Balikpapan. Apabila masing-masing aplikasi tersebut yang } \\
\text { berjalan pada Server JSI Surabaya mengalami incident, maka } \\
\text { hal ini tidak berdampak signifikan pada operasional Sibiru, SI } \\
\text { Iklan, dan SI HRGA karena aplikasi terkait Sibiru, aplikasi } \\
\text { terkait SI Iklan, dan aplikasi terkait SI HRGA masih berjalan } \\
\text { secara aman pada Server JSI Balikpapan (kecuali masing- } \\
\text { masing aplikasi tersebut yang berjalan pada Server JSI } \\
\text { Balikpapan dan/atau Server JSI Balikpapan juga mengalami } \\
\text { incident). }\end{array}$ \\
\hline $\begin{array}{l}\text { Masing- } \\
\text { masing } \\
\text { database } \\
\text { terkait } \\
\text { Sibiru, SI } \\
\text { Iklan, dan SI } \\
\text { HRGA }\end{array}$ & $\begin{array}{l}\text { Sibiru, SI Iklan, } \\
\text { dan SI HRGA }\end{array}$ & Medium & $\begin{array}{l}\text { Database terkait Sibiru, database terkait SI Iklan, dan database } \\
\text { terkait SI HRGA berjalan pada Server JSI Surabaya dan Server } \\
\text { JSI Balikpapan. Apabila masing-masing database tersebut } \\
\text { yang berjalan pada Server JSI Surabaya mengalami incident, } \\
\text { maka hal ini tidak berdampak signifikan pada operasional } \\
\text { Sibiru, SI Iklan, dan SI HRGA karena database terkait Sibiru, } \\
\text { database terkait SI Iklan, dan database terkait SI HRGA masih } \\
\text { berjalan secara aman pada Server JSI Balikpapan (kecuali } \\
\text { masing-masing database tersebut yang berjalan pada Server } \\
\text { JSI Balikpapan dan/atau Server JSI Balikpapan juga } \\
\text { mengalami incident). }\end{array}$ \\
\hline $\begin{array}{l}\text { Server XYZ } \\
\text { Balikpapan } \\
01\end{array}$ & Website XYZ & Medium & $\begin{array}{l}\text { Operasional Website XYZ menggunakan Server XYZ } \\
\text { Balikpapan } 01 \text { (primary server) dan Server XYZ Balikpapan } \\
02 \text { (backup server). Apabila Server XYZ Balikpapan } 01 \\
\text { mengalami incident, hal ini tidak berdampak signifikan pada } \\
\text { operasional Website XYZ karena Server XYZ Balikpapan } 02 \\
\text { masih bisa difungsikan untuk operasional Website XYZ. }\end{array}$ \\
\hline $\begin{array}{l}\text { Server XYZ } \\
\text { Balikpapan } \\
02\end{array}$ & Website XYZ & High & $\begin{array}{l}\text { Walaupun Server XYZ Balikpapan 02 berfungsi sebagai } \\
\text { backup untuk operasional Website XYZ, tetapi Server XYZ } \\
\text { Balikpapan } 01 \text { dan Server XYZ Balikpapan } 02 \text { berada pada } \\
\text { area geografis yang sama (bahkan kedua server tersebut } \\
\text { terletak pada data center yang sama). Penempatan Server XYZ } \\
\text { Balikpapan 01 dan Server XYZ Balikpapan } 02 \text { pada data } \\
\text { center yang sama, tidak sesuai dengan "rule of thumb" } \\
\text { penempatan server yang mengacu pada DRP [24], [25] } \\
\text { sehingga hal ini turut menentukan urgency level pada Server } \\
\text { XYZ Balikpapan } 02 \text { yakni "High" (urgency level pada server } \\
\text { ini semestinya "Medium" jika server ini tidak terletak pada } \\
\text { data center atau bahkan kawasan/wilayah geografis yang sama } \\
\text { dengan Server XYZ Balikpapan 01). }\end{array}$ \\
\hline $\begin{array}{l}\text { Aplikasi } \\
\text { terkait } \\
\text { Website } \\
\text { XYZ }\end{array}$ & Website XYZ & Medium & $\begin{array}{l}\text { Aplikasi terkait Website XYZ berjalan/menggunakan Server } \\
\text { XYZ Balikpapan } 01 \text { dan Server XYZ Balikpapan 02. Apabila } \\
\text { aplikasi terkait Website XYZ yang berjalan pada Server XYZ } \\
\text { Balikpapan } 01 \text { mengalami incident, hal ini tidak berdampak } \\
\text { signifikan pada operasional Website XYZ karena aplikasi } \\
\text { terkait masih berjalan pada Server XYZ Balikpapan } 02 \text { (kecuali } \\
\text { aplikasi terkait pada Server XYZ Balikpapan } 02 \text { dan/atau } \\
\text { Server XYZ Balikpapan } 02 \text { juga mengalami incident). }\end{array}$ \\
\hline $\begin{array}{l}\text { Database } \\
\text { terkait } \\
\text { Website } \\
\text { XYZ }\end{array}$ & Website XYZ & Medium & $\begin{array}{l}\text { Database terkait Website XYZ berjalan/menggunakan Server } \\
\text { XYZ Balikpapan 01 dan Server XYZ Balikpapan 02. Apabila } \\
\text { database terkait Website XYZ yang berjalan pada Server XYZ } \\
\text { Balikpapan } 01 \text { mengalami incident, hal ini tidak berdampak } \\
\text { signifikan pada operasional Website XYZ karena database } \\
\text { terkait masih berjalan pada Server XYZ Balikpapan } 02 \text { (kecuali } \\
\text { database terkait pada Server XYZ Balikpapan } 02 \text { dan/atau } \\
\text { Server XYZ Balikpapan } 02 \text { juga mengalami incident). }\end{array}$ \\
\hline $\begin{array}{l}\text { Server E- } \\
\text { mail } \\
\text { Balikpapan }\end{array}$ & Webmail & High & $\begin{array}{l}\text { Server ini merupakan server satu-satunya yang digunakan oleh } \\
\text { Webmail (operasional IT service ini tidak didukung oleh } \\
\text { backup server) sehingga kondisi ini menjadi riskan apabila } \\
\text { server tersebut mengalami incident. }\end{array}$ \\
\hline $\begin{array}{l}\text { Aplikasi } \\
\text { terkait } \\
\text { Webmail }\end{array}$ & Webmail & High & $\begin{array}{l}\text { Aplikasi terkait Webmail hanya berjalan/menggunakan Server } \\
\text { E-mail Balikpapan sehingga kondisi ini menjadi riskan apabila } \\
\text { aplikasi tersebut mengalami incident. }\end{array}$ \\
\hline $\begin{array}{l}\text { Database } \\
\text { terkait } \\
\text { Webmail }\end{array}$ & Webmail & High & $\begin{array}{l}\text { Database terkait Webmail hanya berjalan/menggunakan Server } \\
\text { E-mail Balikpapan sehingga kondisi ini menjadi riskan apabila } \\
\text { database tersebut mengalami incident. }\end{array}$ \\
\hline
\end{tabular}

Penyusunan SOP Incident Management pada PT. RST dan PT. XYZ Berdasarkan ITIL 3 Versi 2011

(I Putu Deny Arthawan Sugih Prabowo) 
Hasil penentuan incident priority pada studi ini seperti ditunjukkan pada Tabel 11 (termasuk landasan penentuan target response time dan target resolution time pada setiap incident yang terjadi), mengacu pada Konsep Simple Priority Coding System dalam Bagian Incident Prioritization [26].

Tabel 11. Incident priority pada masing-masing CI di PT. RST dan PT. XYZ.

\begin{tabular}{|c|c|c|c|c|}
\hline Nama CI & $\begin{array}{c}\text { IT Service } \\
\text { Provider }\end{array}$ & $\begin{array}{l}\text { Incident } \\
\text { Priority }\end{array}$ & $\begin{array}{c}\text { Target } \\
\text { Response Time }\end{array}$ & $\begin{array}{c}\text { Target } \\
\text { Resolution Time }\end{array}$ \\
\hline Server Nasional & PT. RST & P2 (High) & 30 Menit & 3 Jam \\
\hline $\begin{array}{l}\text { Masing-masing aplikasi terkait } \\
\text { Ipos dan Website RST }\end{array}$ & PT. RST & $\mathrm{P} 2($ High $)$ & 30 Menit & 3 Jam \\
\hline $\begin{array}{l}\text { Masing-masing database terkait } \\
\text { Ipos dan Website RST }\end{array}$ & PT. RST & P2 (High) & 30 Menit & 3 Jam \\
\hline Server Lokal Balikpapan & PT. RST & P2 (High) & 30 Menit & 3 Jam \\
\hline $\begin{array}{l}\text { Masing-masing aplikasi terkait } \\
\text { SIK, SIM SDM, dan E-Pod }\end{array}$ & PT. RST & P2 (High) & 30 Menit & 3 Jam \\
\hline $\begin{array}{l}\text { Masing-masing database terkait } \\
\text { SIK, SIM SDM, dan E-Pod }\end{array}$ & PT. RST & P2 (High) & 30 Menit & 3 Jam \\
\hline Server $\mathrm{C} 2 \mathrm{~A}$ Prima & PT. RST & P1 (Critical) & 10 Menit & $1 \mathrm{Jam}$ \\
\hline Aplikasi terkait E-Pay & PT. RST & $\mathrm{P} 1$ (Critical) & 10 Menit & $1 \mathrm{Jam}$ \\
\hline Database terkait E-Pay & PT. RST & P1 (Critical) & 10 Menit & $1 \mathrm{Jam}$ \\
\hline Server JSI Surabaya & PT. XYZ & P2 (High) & 30 Menit & $3 \mathrm{Jam}$ \\
\hline Server JSI Balikpapan & PT. XYZ & P2 (High) & 30 Menit & 3 Jam \\
\hline $\begin{array}{l}\text { Masing-masing aplikasi terkait } \\
\text { Sibiru, SI Iklan, dan SI HRGA }\end{array}$ & PT. XYZ & P2 (High) & 30 Menit & 3 Jam \\
\hline $\begin{array}{l}\text { Masing-masing database terkait } \\
\text { Sibiru, SI Iklan, dan SI HRGA }\end{array}$ & PT. XYZ & P2 (High) & 30 Menit & 3 Jam \\
\hline Server XYZ Balikpapan 01 & PT. XYZ & $\mathrm{P} 2($ High) & 30 Menit & 3 Jam \\
\hline Server XYZ Balikpapan 02 & PT. XYZ & $\mathrm{P} 1$ (Critical) & 10 Menit & $1 \mathrm{Jam}$ \\
\hline Aplikasi terkait Website XYZ & PT. XYZ & $\mathrm{P} 2$ (High) & 30 Menit & 3 Jam \\
\hline Database terkait Website XYZ & PT. XYZ & P2 (High) & 30 Menit & 3 Jam \\
\hline Server E-mail Balikpapan & PT. XYZ & P2 (High) & 30 Menit & 3 Jam \\
\hline Aplikasi terkait Webmail & PT. XYZ & P2 (High) & 30 Menit & $3 \mathrm{Jam}$ \\
\hline Database terkait Webmail & PT. XYZ & $\mathrm{P} 2$ (High) & 30 Menit & $3 \mathrm{Jam}$ \\
\hline
\end{tabular}

\section{Kesimpulan}

SOP incident management perusahaan (PT. RST dan PT. XYZ) disusun sebagai "alat bantu" perusahaan dalam mengelola/mengontrol incident pada setiap CI yang merupakan penunjang operasional IT services dari perusahaan tersebut. Data kondisi terkini perusahaan dijadikan sebagai referensi utama dalam penyusunan SOP ini. Prosedur penanganan incident dalam SOP ini berkaitan erat dengan penentuan incident priority karena berdasarkan incident priority, incident terbagi atas major incident dan minor incident. Prosedur penanganan incident pada major incident agak berbeda dengan minor incident, termasuk apakah incident perlu dieskalasikan ke layer berikutnya (L2 atau bahkan L3) yang lumrah terjadi pada major incident. Bahkan pada prosedur pasca penanganan incident, Incident Repot wajib disiapkan pada setiap incident yang merupakan major incident sebagai referensi bagi service desk jika incident tersebut berpotensi menjadi problem pada waktu mendatang. Berdasarkan hasil verifikasi SOP ini dengan masingmasing process owner di PT. RST dan PT. XYZ, SOP ini diterima walaupun evaluasi SOP ini akan tetap dilakukan dalam rangka continual improvement (termasuk revisi SOP ini yang akan mengacu pada ITIL 4). Tidak hanya itu, keterbatasan studi ini yang hanya mencakup penyusunan SOP incident management perusahaan berdasarkan ITIL 3 versi 2011, perlu dikembangkan lagi pada studi/riset lain pada waktu mendatang seperti penyusunan SOP problem management, penyusunan SOP change management, dan pengembangan/rancang bangun sistem ticketing pada fungsi service desk (terutama incident management bila hasil studi ini akan dilanjutkan pada pengembangan sistem terkait dalam waktu segera).

\section{Daftar Pustaka}

[1] M. E. Porter, Competitive Advantage: Creating and Sustaining Superior Performance. New York: The Free Press, 1985.

[2] M. Dumas, M. La Rosa, J. Mendling, dan H. A. Reijers, Fundamentals of Business Process Management, II. Berlin: Springer, 2018.

[3] Kantor Kabinet Pemerintah Kerajaan Inggris Raya (Cabinet Office of HM Government), ITIL® Service Strategy, 2011 ed. London: The Stationery Office, 2011.

[4] Kantor Kabinet Pemerintah Kerajaan Inggris Raya (Cabinet Office of HM Government), ITIL® 
Service Design, 2011 ed. London: The Stationery Office, 2011.

[5] Kantor Kabinet Pemerintah Kerajaan Inggris Raya (Cabinet Office of HM Government), ITIL® Service Transition, 2011 ed. London: The Stationery Office, 2011.

[6] Kantor Kabinet Pemerintah Kerajaan Inggris Raya (Cabinet Office of HM Government), ITIL® Service Operation, 2011 ed. London: The Stationery Office, 2011.

[7] Kantor Kabinet Pemerintah Kerajaan Inggris Raya (Cabinet Office of HM Government), ITIL® Continual Service Improvement, 2011 ed. London: The Stationery Office, 2011.

[8] AXELOS, ITIL® Foundation ITIL 4 Edition. London: The Stationery Office, 2019.

[9] L. E. Conde-Zhingre, P. A. Quezada- Sarmiento, dan W. Hernandez, "Architecture Proposal of Help Desk based on the framework ITIL 3.0," in 2019 14th Iberian Conference on Information Systems and Technologies (CISTI), 2019, hal. 1-6.

[10] M. Bosu, D. Abuaiadah, P. Khanna, S. Nepia, dan D. Palmer, "Evaluation of IT Service Desk: A Case Study," in The 10th Annual Computing and Information Technology Research and Education New Zealand Conference (CITRENZ 2019), 2019, hal. 73-80.

[11] M. Marrone dan M. Hammerle, "Relevant Research Areas in IT Service Management: An Examination of Academic and Practitioner Literatures," Commun. Assoc. Inf. Syst., vol. 41, no. 1, hal. 517-543, 2017.

[12] T. R. Eikebrokk dan J. Iden, "Strategising IT service management through ITIL implementation: model and empirical test," Total Qual. Manag. Bus. Excell., vol. 28, no. 3-4, hal. 238-265, Feb 2017.

[13] K. Wainwright dan C. Power, "Adventures in Starting a Service Desk," in Proceedings of the 2016 ACM SIGUCCS Annual Conference, 2016, hal. 11-14.

[14] I. K. Raharjana, I. Ibadillah, Purbandini, dan E. Hariyanti, "Incident and service request management for academic information system based on COBIT," in International Conference on Electrical Engineering, Computer Science and Informatics (EECSI), 2018, hal. 421-425.

[15] V. R. Palilingan dan J. R. Batmetan, "Incident Management in Academic Information System using ITIL Framework," in IOP Conference Series: Materials Science and Engineering, 2018, hal. 1-9.

[16] M. T. Dharmawan, H. T. Sukmana, L. K. Wardhani, Y. Ichsani, dan I. Subchi, "The Ontology of IT Service Management by Using ITILv.3 Framework: A Case Study for Incident Management," in 2018 Third International Conference on Informatics and Computing (ICIC), 2018, hal. 1-5.

[17] L. Lema-Moreta dan J. Calvo-Manzano, "A Proposal for Implementation of ITIL Incident Management Process in SMEs," in 2017 IEEE Second Ecuador Technical Chapters Meeting (ETCM), 2017, hal. 1-5.

[18] A. D. Nugraha dan N. Legowo, "Implementation of Incident Management for Data Services Using ITIL V3 in Telecommunication Operator Company," in 2017 International Conference on Applied Computer and Communication Technologies (ComCom), 2017, hal. 1-6.

[19] D. S. Ilvarianto dan N. Legowo, "Incident Management Implementation Using Continual Service Improvement Method at PT AOP Dionisius," in 2017 International Conference on Applied Computer and Communication Technologies (ComCom), 2017, hal. 1-7.

[20] Y. Lisanti, D. Luhukay, dan V. Mariani, "IT Service and Risk Management Implementation for Online Startup SME (Case Study : Online Startup SME in Jakarta)," in 2017 International Conference on Information Management and Technology (ICIMTech), 2017, hal. 300-303.

[21] A. F. Rizky, A. Herdiyanti, dan T. D. Susanto, "Pembuatan Prosedur Operasional Standar Pengelolaan Insiden pada Government Resources Management Systems Kota Surabaya Berdasarkan ITIL V3," SISFO, vol. 06, no. 02, hal. 199-214, 2017.

[22] Kantor Kabinet Pemerintah Kerajaan Inggris Raya (Cabinet Office of HM Government), "Incident Management Roles - Organizing for Service Operation," in ITIL® Service Operation, 2011 ed., London: The Stationery Office, 2011, hal. 194-195.

[23] Kantor Kabinet Pemerintah Kerajaan Inggris Raya (Cabinet Office of HM Government), "Responsibility Model (RACI) - Organizing for Service Operation," in ITIL® Service Operation, 2011 ed., London: The Stationery Office, 2011, hal. 203-204.

[24] K. Jayaswal, Administering Data Centers: Servers, Storage, and Voice over IP. Indianapolis: Wiley Publishing, Inc., 2006.

[25] P. Gregory, IT Disaster Recovery Planning for Dummies. Indianapolis: Wiley Publishing, Inc., 2008.

[26] Kantor Kabinet Pemerintah Kerajaan Inggris Raya (Cabinet Office of HM Government), "Incident Prioritization - Service Operation Processes," in ITIL® Service Operation, 2011 ed., London: The Stationery Office, 2011, hal. 79-80.

Penyusunan SOP Incident Management pada PT. RST dan PT. XYZ Berdasarkan ITIL 3 Versi 2011

(I Putu Deny Arthawan Sugih Prabowo) 